\title{
Diagnosis-linked antibiotic prescribing in Swedish primary care - a comparison between in-hours and out-of-hours
}

\author{
Olof Cronberg ${ }^{1,2,3^{*}}$ (D) Mia Tyrstrup ${ }^{3,4}$ (D), Kim Ekblom ${ }^{2,5}$ (D) and Katarina Hedin ${ }^{3,6}$ (D)
}

\begin{abstract}
Background: The rise in antibiotic resistance is a global public health concern, and antibiotic overuse needs to be reduced. Earlier studies of out-of-hours care have indicated that antibiotic prescribing is less appropriate than that of in-hours care. However, no study has compared the out-of-hours treatment of infections to in-hours treatment within the same population.
\end{abstract}

Methods: This retrospective, descriptive study was based on data retrieved from the Kronoberg Infection Database in Primary Care (KIDPC), which consists of all visits to primary care with an infection diagnosis or prescription of antibiotics during 2006-2014. The purpose was to study the trends in antibiotic prescribing and to compare consultations and prescriptions between in-hours and out-of-hours.

Results: The visit rate for all infections was 434 visits per 1000 inhabitants per year. The visit rate was stable during the study period, but the antibiotic prescribing rate decreased from 266 prescriptions per 1000 inhabitants in 2006 to 194 prescriptions in 2014 (mean annual change -8.5 [95\% Cl - 11.9 to - 5.2]). For the out-of-hours visits (12\% of the total visits), a similar reduction in antibiotic prescribing was seen. The decrease was most apparent among children and in respiratory tract infections.

When antibiotic prescribing during out-of-hours was compared to in-hours, the unadjusted relative risk of antibiotic prescribing was 1.37 (95\% Cl 1.36 to 1.38), but when adjusted for age, sex, and diagnosis, the relative risk of antibiotic prescribing was 1.09 (95\% Cl 1.08 to 1.10). The reduction after adjustment was largely explained by a higher visit rate during out-of-hours for infections requiring antibiotics (acute otitis media, pharyngotonsillitis, and lower urinary tract infection). The choices of antibiotics used for common diagnoses were similar.

Conclusions: Although the infection visit rate was unchanged over the study period, there was a significant reduction in antibiotic prescribing, especially to children and for respiratory tract infections. The higher antibiotic prescribing rate during out-of-hours was small when adjusted for age, sex, and diagnosis. No excess prescription of broad-spectrum antibiotics was seen. Therefore, interventions selectively aiming at out-of-hours centres seem to be unmotivated in a low-prescribing context.

Keywords: Antibiotic prescribing, Diagnosis-linked prescription, Electronic health records, Infectious disease, Inhours, Out-of-hours service, Primary care

\footnotetext{
* Correspondence: olof.cronberg@med.lu.se

'Växjöhälsan Primary Healthcare Center, VC Växjöhälsan, Hjortvägen 1, 35245

Växjö, Sweden

${ }^{2}$ Department of Research and Development, Region Kronoberg, Växjö,

Sweden

Full list of author information is available at the end of the article
}

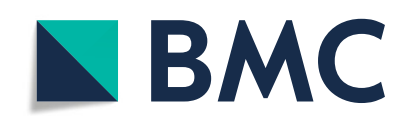

(c) The Author(s). 2020 Open Access This article is licensed under a Creative Commons Attribution 4.0 International License, which permits use, sharing, adaptation, distribution and reproduction in any medium or format, as long as you give appropriate credit to the original author(s) and the source, provide a link to the Creative Commons licence, and indicate if changes were made. The images or other third party material in this article are included in the article's Creative Commons licence, unless indicated otherwise in a credit line to the material. If material is not included in the article's Creative Commons licence and your intended use is not permitted by statutory regulation or exceeds the permitted use, you will need to obtain permission directly from the copyright holder. To view a copy of this licence, visit http://creativecommons.org/licenses/by/4.0/. The Creative Commons Public Domain Dedication waiver (http://creativecommons.org/publicdomain/zero/1.0/) applies to the data made available in this article, unless otherwise stated in a credit line to the data. 


\section{Background}

The rise of antibiotic resistance is a global public health threat according to the World Health Organization [1], and antibiotic overuse is common and results in medicalization, unnecessary costs, and increased antibiotic resistance [2]. However, studies on antibiotic prescribing in primary care regardless of indication show a high level of variability between physicians in different countries [3-5].

In primary care in-hours (IH) are usually office hours (in Sweden 08:00 to 17:00) during business days, and out-of-hours $(\mathrm{OOH})$ are the remaining hours. Earlier studies of $\mathrm{OOH}$ care have suggested that compared to IH care there are lower adherence to antibiotic guidelines $[6,7]$, a higher antibiotic prescribing rate $[8,9]$, a higher rate of prescriptions for broad-spectrum antibiotics [8], and more antibiotic prescriptions during weekends than weekday evenings [10]. In a qualitative study from Belgium, the physicians reported that the threshold for prescribing antibiotics was lower during $\mathrm{OOH}$, but the choice of antibiotics was the same [11]. A more recent Belgian $\mathrm{OOH}$ study showed a high antibiotic prescribing rate for all indications, a high rate of not using recommended antibiotics, and an overuse of quinolones [12]. However, a Dutch study found the prescribing quality to be appropriate, and the higher rates of prescribing in $\mathrm{OOH}$ were explained by a different population of presenting patients [13]. No previous study has compared the $\mathrm{OOH}$ treatment of infections to $\mathrm{IH}$ within the same population.

Although Sweden belongs to the European countries with low levels of antibiotic prescriptions, there is still room for improvement [14]. Previous registry-based studies in Sweden have shown a significant reduction in antibiotic prescriptions over the last decade, but these studies have not included OOH [15-17]. Several Swedish national guidelines concerning the evaluation and treatment of infectious diseases have been published [18-22], and generally these guidelines aim at better diagnostics, fewer antibiotics, and more targeted treatments.

Because visits for infectious diseases are common at $\mathrm{OOH}$ centres, it is important to evaluate whether $\mathrm{OOH}$ visits are associated with increased antibiotic prescribing rates because this would warrant interventions in $\mathrm{OOH}$ settings.

The purpose of the study was to describe the trends in antibiotic prescribing over time and to compare diagnosis-linked prescribing in general and in detail between $\mathrm{IH}$ and $\mathrm{OOH}$ in the same population.

\section{Methods}

\section{Description of the study population}

In 2014, Kronoberg County in southern Sweden had 189,128 inhabitants, which was equal to $2 \%$ of the
Swedish population [23]. During 2014, there were a total of 243,502 physician visits for all causes and 238,164 other visits (nurses, physiotherapists, behavioural therapists) in primary care, thus there were 1300 physician visits and 1300 other visits per 1000 inhabitants.

During the study period, the number of primary healthcare centres (PHCCs) varied between 28 and 35, with 1-8 family physicians each. There were approximately 100 family physician positions and 50 junior physician positions. At the study start, all PHCCs were publicly run, but since March 2009 a third of the PHCCs have been privately run due to new legislation allowing publicly funded private PHCCs.

At the PHCCs, the patient normally booked an appointment through a telephone call with an office nurse who assessed if the patient needed a physician visit. IH were business days 08:00 to 17:00. In the region there were two $\mathrm{OOH}$ centres (OOHCs), and the PHCCs staffed the $\mathrm{OOHCs}$ with physicians. Patients were supposed to call a nurse triage first, but could also walk in. The visit fees were the same as for $\mathrm{IH}$ visits. Home visits were rare, and usually only performed for urgent cases at elderly care homes. Nurses at the OOHCs were responsible for phone advice, and there was also a national phone advice number for patients where nurses provided medical advice. At the time of the study, no Internet services were available.

OOHC 1 served approximately 125,000 inhabitants and was situated in the neighbourhood of the hospital in city 1. During 2006-2007 the centre was open from 17: 00 to 24:00 on weekdays and from 08:00 to 24:00 on weekends and holidays. From 2008 the centre closed at 21:00. Walk-in patients met a nurse who assessed whether a meeting with a physician was warranted.

OOHC 2 served approximately 63,000 inhabitants and was situated at the emergency department of the hospital in city 2. During 2006-2007 the centre was open from 17:00 to 08:00 on weekdays and around the clock on weekends and holidays. From 2008 the centre closed at 21:00. Walk-in patients generally got to see a physician.

\section{The Kronoberg infection database in primary care (KIDPC)} This retrospective, descriptive study was based on data from the KIDPC database, which contains information on all visits with an infection diagnosis and all antibiotic prescriptions with or without a visit in primary care in Kronoberg County in 2006-2014. Annually, there were on average 86,000 visits for infections and 43,000 antibiotic prescriptions reported in the database.

The data in the KIDPC were extracted from the electronic medical records (EMR) used in Kronoberg County (Cambio Cosmic software, Cambio Healthcare Systems AB, Linköping, Sweden) at one instance in 2015 using 
BusinessObjects (SAP AG, Walldorf, Germany). These data contain detailed information about the patients (age, sex, anonymous ID), the visits (PHCC, geography, $\mathrm{IH}$ or $\mathrm{OOH}$ ), the care providers (physicians, nurses), the investigations (diagnostic tests, x-rays, cultures), and the prescriptions (drugs, dosages, durations). The data were linked together using the anonymous patient ID and visit date. For all physician visits, at least one diagnosis was registered according to the simplified Swedish primary care edition of the International Classification of Disease and Related Health Problems - Tenth Revision (ICD-10) [24]. The diagnoses were validated and grouped into four main groups and several subgroups by one of the authors $(\mathrm{OC})$ according to recommendations by Public Health Agency of Sweden [25]. The main groups are respiratory tract infections (RTIs), urinary tract infections (UTIs), skin and soft tissue infections (SSIs), and other infections. The RTI group includes ear infections, and the UTI group includes urogenital infections. The other infections group includes eye infections, gastrointestinal infections, and rare infections (See Additional file 1). Because at least one diagnosis had to be recorded for each physician visit, the data set is considered to be complete. However, no diagnoses were recorded for phone, mail or e-mail consultations, and in these cases, the prescriptions could not be linked to a diagnosis.

Antibiotic prescriptions were identified according to Anatomical Therapeutic Chemical Classification (ATC) code group J01, which includes all oral and parenteral antibiotics, but not antibiotics in ointments or eye drops. Antibiotic prescriptions were linked to diagnoses if within a week after a visit. Antibiotic treatment without a diagnosis of an infection could also result from consultation with a care provider other than a physician or from a non-infection diagnosis at a visit. Information on whether the patients collected the medication at the pharmacies was not available in the present study.

\section{Data set}

All physician visits with an infection diagnosis and all antibiotic prescriptions were extracted from the KIDPC database, resulting in a data set with 702,048 physician visits and 389,263 prescriptions over 9 years. For each visit, data on the patient's age and sex, infection diagnoses, antibiotic treatments, and PHCC were extracted.

A visit was defined as a physical visit to a physician, and a consultation was defined as a phone, mail, e-mail or nurse contact. It was compulsory for the physician to code the diagnosis when documenting the visit. Only physician coded diagnoses were used in this study for consistency. In $3 \%$ of the visits more than one infection diagnosis was recorded, and in these cases the main diagnosis was selected based on the severity and the likelihood of the diagnosis resulting in an antibiotic prescription. Consultations were not coded for diagnoses, but could in some instances result in antibiotic prescriptions, for example treatment for UTI or repeat prescriptions.

This study presents descriptive annual data and mean annual change for infections and antibiotic prescribing per 1000 inhabitants divided per main infection group, age group, sex, and per $\mathrm{IH}$ and $\mathrm{OOH}$ (Tables 1, 2, 3, 4). The data are presented as numbers per 1000 inhabitants per year based on the population of the region as of December 31 of each year. Because the population of Kronoberg County is only $2 \%$ of the population of Sweden and the antibiotic prescription rate was lower than the average in Sweden [26], the numbers reported cannot be extrapolated to the national level. However, the trends are likely to be generalisable.

The $\mathrm{IH}$ and the $\mathrm{OOH}$ cohorts were compared. The relative risk of receiving antibiotics during $\mathrm{OOH}$ was calculated (Table 5). The proportions of the choice of antibiotics for common infections were reported (Table 6).

\section{Statistical methods}

All analyses were performed using Excel 2013 (Microsoft, Redmond, WA, USA) and SPSS Version 23 (IBM Corp, Armonk, NY, USA). For descriptive statistics, means, and proportions were used. For annual trends, linear regressions were calculated and presented as mean annual change with 95\% confidence interval. Comparisons between groups after adjusting for sex, age, and diagnosis were presented as relative risks with $95 \%$ confidence interval. Comparisons between proportions of categorical variables in two independent groups were performed with the chi-square test. $P$-values $\leq .05$ were considered statistically significant.

\section{Results}

The physician visit rate for infections varied during the study and reached a maximum of 469 visits per 1000 inhabitants per year in 2011 and a minimum of 398 visits in 2014. Female patients have more infection visits than male patients, 502 and 366 visits per 1000 inhabitants per year respectively. Children 0-4 years and adults over 80 years had the highest visit rates, 995 and 576 visits per 1000 inhabitants per year respectively. No significant trends were observed in total visit rate nor in visit rate by sex, but the mean annual change in visit rate per 1000 inhabitants per year decreased in children 0-4 years $(-33.7$ (95\% CI -56.0 to -11.5$)$ ), increased in adults $65-79$ years $(7.7$ (95\% CI 1.1 to 14.3$)$ and in adults over 80 years (13.9 (95\% CI 7.6 to 20.2)) (Tables 1 and 2). 
Table 1 Visits according to the type of infection per 1000 inhabitants per year

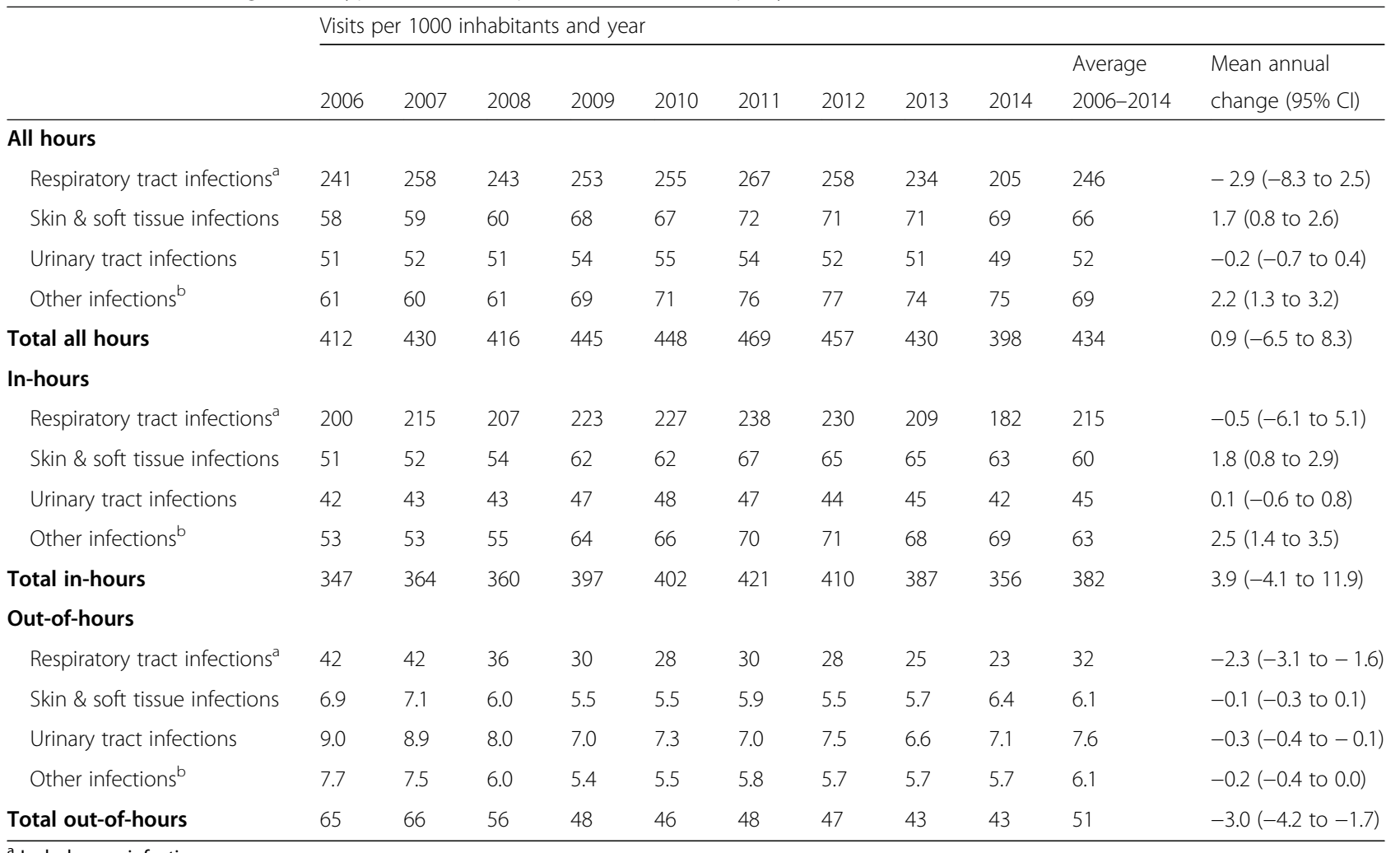

ancludes ear infections

${ }^{\mathrm{b}}$ Includes eye infections, gastrointestinal infections, and rare infections

The antibiotic prescriptions per 1000 inhabitants per year decreased significantly from 266 prescriptions in 2006 to 194 prescriptions in 2014 (mean annual change -8.5 (95\% CI -11.9 to -5.2$)$ ). There was no sex difference, but the decrease in antibiotic prescriptions was more pronounced in children $0-4$ years (mean annual change -35.2 (95\% CI -46.9 to -23.5$)$ ) and in children 5-19 years (mean annual change - 11.7 (95\% CI -17.0 to -6.5$)$. The antibiotic prescribing frequency decreased mainly for RTIs (mean annual change -6.5 (95\% CI -9.0 to -3.9$)$ ), explaining $76 \%$ of the total reduction. Antibiotic prescriptions without an infection diagnosis and prescriptions for UTIs also decreased, explaining a further 11 and $8 \%$ of the total reduction, respectively (Tables 3 and 4 ).

Of all antibiotic prescriptions, $75 \%$ were linked to an infection visit on the same day, another $3 \%$ were linked to an infection visit within a week before the prescription day, and finally $22 \%$ were not possible to link to an infection visit. These proportions were stable during the study period. Of all antibiotics prescribed at visits, $66 \%$ were antibiotics commonly used for RTIs, $12 \%$ were commonly used for SSIs, $16 \%$ were commonly used for UTIs, and 6\% were other antibiotics. Of the antibiotics prescribed without an infection diagnosis, $38 \%$ were antibiotics commonly used for RTIs, $25 \%$ were commonly used for SSIs, $29 \%$ were commonly used for UTIs, and $8 \%$ were other antibiotics. Of the UTI antibiotics, $36 \%$ were prescribed without an infection diagnosis.

During the study period, the $\mathrm{OOH}$ infection visits decreased from 65 visits per 1000 inhabitants in 2006 to 43 visits in 2014 (mean annual change -3.0 visits (95\% CI -4.2 to -1.7$)$ ). Also, the antibiotic prescribing decreased from 43 prescriptions per 1000 inhabitants in 2006 to 26 prescriptions in 2014 (mean annual change -2.2 prescriptions (95\% CI -3.3 to -1.2$)$ ).

The diagnoses and antibiotic prescription rates between $\mathrm{IH}$ and $\mathrm{OOH}$ are shown in Table 5. During $\mathrm{IH}$, there were 382 infection visits per 1000 inhabitants per year compared to 51.4 during $\mathrm{OOH}$. Thus $12 \%$ of all visits were during $\mathrm{OOH}$. RTIs were the most common diagnoses during both $\mathrm{IH}$ and $\mathrm{OOH}$. However, acute otitis media, pharyngotonsillitis, and lower UTIs were more common during $\mathrm{OOH}$. A total of $15 \%$ of all antibiotics were prescribed during $\mathrm{OOH}$. The likelihood of receiving an antibiotic prescription was $55 \%$ during $\mathrm{OOH}$ visits compared to $41 \%$ during $\mathrm{IH}$ visits. The unadjusted relative risk of antibiotic prescribing in $\mathrm{OOH}$ was 1.37 (95\% CI 1.36 to 1.38 ) compared to $\mathrm{IH}$. The difference remained unchanged when only adjusted for age and sex 1.37 (95\% CI 1.37 to 1.38 ) and 1.37 (95\% CI 1.37 to 1.38), respectively. However, when adjusted for age, sex, 
Table 2 Visits due to infections according to sex and age group per 1000 inhabitants per year

\begin{tabular}{|c|c|c|c|c|c|c|c|c|c|c|c|}
\hline & \multicolumn{11}{|c|}{ Visits per 1000 inhabitants per year } \\
\hline & & & & & & & & & & Average & Mean annual \\
\hline & 2006 & 2007 & 2008 & 2009 & 2010 & 2011 & 2012 & 2013 & 2014 & 2006-2014 & change $(95 \% \mathrm{Cl})$ \\
\hline \multicolumn{12}{|l|}{ All hours } \\
\hline Female & 477 & 499 & 481 & 514 & 517 & 546 & 528 & 500 & 458 & 502 & 0.9 (-8.0 to 9.8$)$ \\
\hline Male & 345 & 369 & 351 & 376 & 380 & 393 & 386 & 362 & 336 & 366 & $0.5(-5.9$ to 6.8$)$ \\
\hline \multicolumn{12}{|l|}{ Age (years) } \\
\hline $0-4$ & 997 & 1172 & 1062 & 1059 & 1079 & 962 & 958 & 867 & 796 & 995 & $-33.7(-56.0$ to -11.5$)$ \\
\hline $5-19$ & 494 & 498 & 451 & 481 & 492 & 511 & 468 & 433 & 382 & 468 & -9.7 ( -19.6 to 0.3$)$ \\
\hline $20-39$ & 376 & 383 & 353 & 381 & 377 & 406 & 393 & 357 & 331 & 373 & $-2.5(-9.5$ to 4.5$)$ \\
\hline $40-64$ & 319 & 329 & 315 & 348 & 349 & 379 & 368 & 356 & 326 & 343 & $4.1(-2.2$ to 10.4$)$ \\
\hline $65-79$ & 404 & 407 & 396 & 432 & 428 & 471 & 474 & 460 & 431 & 434 & 7.7 (1.1 to 14.3$)$ \\
\hline$\geq 80$ & 506 & 522 & 552 & 570 & 578 & 610 & 632 & 616 & 595 & 576 & 13.9 (7.6 to 20.2) \\
\hline \multicolumn{12}{|l|}{ In-hours } \\
\hline Female & 403 & 425 & 418 & 460 & 464 & 492 & 475 & 451 & 410 & 444 & $4.2(-5.3$ to 13.7$)$ \\
\hline Male & 288 & 311 & 303 & 334 & 340 & 351 & 346 & 324 & 299 & 322 & $3.1(-3.7$ to 9.9$)$ \\
\hline \multicolumn{12}{|l|}{ Age (years) } \\
\hline $0-4$ & 720 & 889 & 851 & 884 & 911 & 816 & 813 & 736 & 666 & 810 & $-13.7(-38.6$ to 11.2$)$ \\
\hline $5-19$ & 375 & 392 & 373 & 412 & 426 & 440 & 403 & 373 & 327 & 391 & $-2.7(-13.5$ to 8.1$)$ \\
\hline 20-39 & 296 & 313 & 299 & 335 & 332 & 357 & 345 & 313 & 286 & 320 & $1.3(-6.5$ to 9.0$)$ \\
\hline $40-64$ & 274 & 287 & 282 & 319 & 320 & 347 & 337 & 326 & 297 & 310 & $5.9(-0.8$ to 12.5$)$ \\
\hline $65-79$ & 368 & 371 & 369 & 407 & 405 & 445 & 449 & 436 & 406 & 406 & 9.1 (2.4 to 15.8$)$ \\
\hline$\geq 80$ & 464 & 482 & 515 & 540 & 551 & 582 & 603 & 589 & 568 & 544 & 16.0 (9.2 to 22.8 ) \\
\hline \multicolumn{12}{|c|}{ Out-of-hours } \\
\hline Female & 74 & 74 & 63 & 54 & 52 & 54 & 53 & 49 & 48 & 58 & $-3.3(-4.7$ to -1.9$)$ \\
\hline Male & 56 & 58 & 49 & 42 & 40 & 42 & 40 & 38 & 37 & 45 & $-2.6(-3.7$ to -1.6$)$ \\
\hline \multicolumn{12}{|l|}{ Age (years) } \\
\hline $0-4$ & 277 & 283 & 211 & 175 & 168 & 146 & 145 & 130 & 131 & 185 & $-20.0(-27.3$ to -12.7$)$ \\
\hline $5-19$ & 119 & 106 & 78 & 68 & 66 & 71 & 65 & 60 & 55 & 77 & $-7.0(-10.4$ to -3.6$)$ \\
\hline $20-39$ & 80 & 70 & 54 & 46 & 45 & 49 & 48 & 45 & 45 & 53 & $-3.7(-6.2$ to -1.3$)$ \\
\hline $40-64$ & 45 & 42 & 34 & 29 & 29 & 32 & 31 & 30 & 29 & 33 & $-1.8(-3.0$ to -0.6$)$ \\
\hline $65-79$ & 36 & 35 & 27 & 25 & 22 & 26 & 25 & 24 & 24 & 27 & $-1.4(-2.5$ to -0.4$)$ \\
\hline$\geq 80$ & 42 & 40 & 37 & 30 & 27 & 28 & 29 & 27 & 26 & 32 & $-2.1(-2.9$ to -1.2$)$ \\
\hline
\end{tabular}

and diagnosis the relative risk of antibiotic prescribing during $\mathrm{OOH}$ was 1.09 (95\% CI 1.08 to 1.10) compared to IH. No difference was found between the two $\mathrm{OOHCs.} \mathrm{Age} \mathrm{and} \mathrm{sex} \mathrm{adjusted} \mathrm{relative} \mathrm{risks} \mathrm{of} \mathrm{antibiotic}$ prescribing during $\mathrm{OOH}$ per diagnosis were significantly higher for acute otitis media, pharyngotonsillitis, pneumonia, SSI and UTI.

For the six most common diagnoses treated with antibiotics, a comparison of treatment choice per diagnosis with $\mathrm{IH}$ and $\mathrm{OOH}$ visits was made. The prescription rate was higher during $\mathrm{OOH}$ for pneumonia, acute otitis media, and pharyngotonsillitis. Although the difference was statistically significant, the choices of treatment for each diagnosis were comparable between $\mathrm{IH}$ and $\mathrm{OOH}$ prescriptions (Table 6).

\section{Discussion}

During the study period, the level of infection visits was constant, but the antibiotic prescription rate decreased. Fewer prescriptions in children and for RTIs were the main reasons for the reduction. During $\mathrm{OOH}$, there was a reduction both in infection visits and in antibiotic prescribing. The antibiotic prescription rate was higher during $\mathrm{OOH}$ than during $\mathrm{IH}$, and when adjusting for age, sex, and diagnosis the difference was significant but small. The choices of treatments were similar. 
Table 3 Antibiotic prescriptions according to the type of infection per 1000 inhabitants per year

\begin{tabular}{|c|c|c|c|c|c|c|c|c|c|c|c|}
\hline & \multicolumn{11}{|c|}{ Antibiotic prescriptions per 1000 inhabitants per year } \\
\hline & & & & & & & & & & Average & Mean annual \\
\hline & 2006 & 2007 & 2008 & 2009 & 2010 & 2011 & 2012 & 2013 & 2014 & $2006-2014$ & change $(95 \% \mathrm{Cl})$ \\
\hline \multicolumn{12}{|l|}{ All hours } \\
\hline Respiratory tract infections ${ }^{a}$ & 124 & 135 & 114 & 109 & 111 & 109 & 103 & 85 & 70 & 107 & $-6.5(-9.0$ to -3.9$)$ \\
\hline Skin \& soft tissue infections & 31 & 32 & 29 & 33 & 30 & 32 & 29 & 30 & 28 & 30 & $-0.3(-0.7$ to 0.1$)$ \\
\hline Urinary tract infections & 44 & 44 & 41 & 44 & 45 & 43 & 40 & 40 & 38 & 42 & $-0.7(-1.2$ to -0.1$)$ \\
\hline Other infections ${ }^{b}$ & 4.5 & 4.8 & 4.3 & 4.4 & 4.4 & 4.9 & 3.9 & 3.3 & 3.4 & 4.2 & $-0.1(-0.3$ to 0.0$)$ \\
\hline Without infection diagnosis ${ }^{c}$ & 62 & 63 & 60 & 58 & 57 & 57 & 59 & 55 & 55 & 58 & $-0.9(-1.4$ to -0.5$)$ \\
\hline Total all hours & 266 & 278 & 248 & 249 & 247 & 246 & 236 & 213 & 194 & 242 & $-8.5(-11.9$ to -5.2$)$ \\
\hline \multicolumn{12}{|l|}{ In-hours } \\
\hline Respiratory tract infections ${ }^{a}$ & 101 & 109 & 94 & 93 & 95 & 93 & 88 & 73 & 59 & 89 & $-4.8(-7.1$ to -2.5$)$ \\
\hline Skin \& soft tissue infections & 26 & 26 & 25 & 29 & 26 & 28 & 26 & 26 & 24 & 26 & $-0.2(-0.7$ to 0.3$)$ \\
\hline Urinary tract infections & 37 & 36 & 34 & 38 & 38 & 37 & 34 & 34 & 32 & 36 & $-0.5(-1.1$ to 0.1$)$ \\
\hline Other infections ${ }^{\mathrm{b}}$ & 4.0 & 4.3 & 3.9 & 4.1 & 4.0 & 4.4 & 3.5 & 3.0 & 3.2 & 3.8 & $-0.1(-0.2$ to 0.0$)$ \\
\hline Without infection diagnosis ${ }^{c}$ & 55 & 57 & 55 & 55 & 54 & 53 & 55 & 51 & 50 & 54 & $-0.7(-1.1$ to -0.3$)$ \\
\hline Total in-hours & 223 & 233 & 212 & 219 & 217 & 216 & 205 & 186 & 168 & 209 & $-6.3(-9.6$ to -3.0$)$ \\
\hline \multicolumn{12}{|l|}{ Out-of-hours } \\
\hline Respiratory tract infections ${ }^{a}$ & 23 & 26 & 21 & 16 & 16 & 16 & 16 & 12 & 11 & 17 & $-1.7(-2.3$ to -1.1$)$ \\
\hline Skin \& soft tissue infections & 4.6 & 5.1 & 4.1 & 3.8 & 3.8 & 4.0 & 3.9 & 3.9 & 4.0 & 4.1 & $-0.1(-0.2$ to 0.0$)$ \\
\hline Urinary tract infections & 7.3 & 7.6 & 6.6 & 5.9 & 6.1 & 5.9 & 6.5 & 5.6 & 6.0 & 6.4 & $-0.2(-0.3$ to 0.0$)$ \\
\hline Other infections ${ }^{b}$ & 0.4 & 0.5 & 0.4 & 0.3 & 0.5 & 0.4 & 0.4 & 0.3 & 0.3 & 0.4 & $0.0(0.0$ to 0.0$)$ \\
\hline Without infection diagnosis ${ }^{c}$ & 7.2 & 5.9 & 4.1 & 3.6 & 3.3 & 3.7 & 4.2 & 4.4 & 4.5 & 4.5 & $-0.3(-0.6$ to 0.1$)$ \\
\hline Total out-of-hours & 43 & 45 & 36 & 30 & 30 & 30 & 31 & 27 & 26 & 33 & $-2.2(-3.3$ to -1.2$)$ \\
\hline
\end{tabular}

ancludes ear infections

b Includes eye infections, gastrointestinal infections, and rare infections

c Prescriptions with non-infection diagnosis or no diagnosis registered

This study showed that women visited primary care for infections more often than men and also received antibiotic treatment more often than men. The same pattern has been seen in other studies from Denmark, the Netherlands, and the United Kingdom [10, 27, 28]. The sex difference in the incidence of lower UTI was an important reason.

Our data on visit rates per 1000 inhabitants per years for infections were similar to the Primary Care Record of Infections in Sweden (PRIS) database [15], which consists of data since 2007 on visits with an infectious diagnosis and all antibiotic prescriptions from voluntarily participating PHCCs on an annual basis. Antibiotic prescriptions are in most cases linked to diagnoses and also includes information about age, sex, and laboratory results. The database has a larger dataset than in this study covering PHCCs in other regions but lacks $\mathrm{OOH}$ data. In the PRIS database, the visit rates per 1000 persons per year for infections during IH were 457 (in 2008), 441 (in 2010), and 406 (in 2013).

The total antibiotic prescribing in primary care decreased by $27 \%$ in this study. However, in the PRIS database [15] the reduction of $\mathrm{IH}$ antibiotic prescribing was $36 \%$, as the $\mathrm{IH}$ antibiotic prescription per 1000 persons per year decreased from 245 (in 2008) to 201 (in 2010) to 157 (in 2013). For the corresponding years in our study, the IH antibiotic prescriptions per 1000 inhabitants were 212,217 , and 186 , respectively. It is possible that participation in the PRIS database could have triggered a more restrictive antibiotic prescribing behaviour compared to our real-life study. A Finnish study [29] reported a $47 \%$ reduction in antibiotic prescriptions to children in primary and other out-patient care between 2010 and 2016, whereas our present study showed a $38 \%$ reduction in children in primary care between 2010 and 2014.

Several explanations are possible for the reduction in antibiotics prescriptions. For example, there might be increasing awareness among the general public that the use of antibiotics should be avoided when they are not needed. Also, physicians might have become more restrictive in prescribing. Another reason might be due to the antibiotic stewardship work performed by the Strama group, the Swedish strategic programme against 
Table 4 Antibiotic prescription according to sex and age group per 1000 inhabitants per year

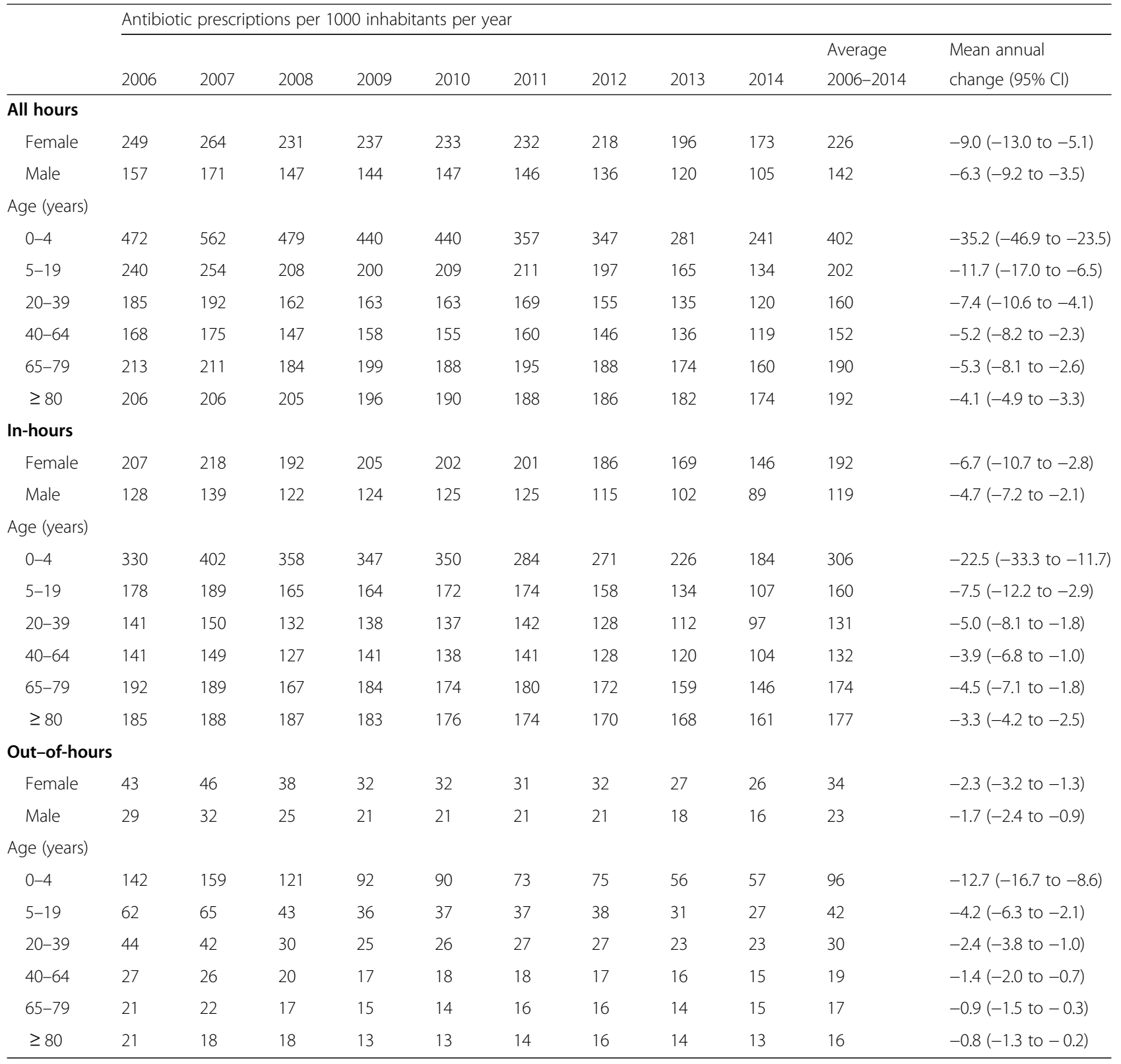

antibiotic resistance [30]. In 2005, Strama together with the government launched a national strategy to prevent antibiotic resistance and healthcare-associated infections. Several actions have been performed in relation to this strategy. Diagnosis-specific guidelines for optimal antibiotic use have been published and promoted, and the use of antibiotics has been reported at the local, regional, and national level [17, 31]. During 2011-2014, the Swedish government ran a patient safety campaign aiming to decrease antibiotic use with the goal of fewer than 250 annual prescriptions in out-patient care per 1000 inhabitants for all prescribers together (primary and secondary care, dental care) resulting in a decrease from 385 prescriptions (2011) to 328 prescriptions (2014) [26, 32]. Furthermore, a pneumococcal conjugate vaccine was introduced in the Swedish national vaccination programme for children in 2009. Finally, a national economic bonus system was introduced for regions achieving a reduction in the antibiotic prescription levels, and incentive for quality outcome with the same goal was introduced in 2011 at the PHCC level in Kronoberg County.

During the period studied here, the number of $\mathrm{OOH}$ infection visits decreased by a third. Factors contributing 
Table 5 Visits and antibiotic prescriptions per diagnosis for in-hours compared to out-of-hours

\begin{tabular}{|c|c|c|c|c|c|c|c|}
\hline \multirow[t]{3}{*}{ Diagnoses } & \multicolumn{3}{|l|}{ In-hours } & \multicolumn{4}{|l|}{ Out-of-hours } \\
\hline & \multirow{2}{*}{$\begin{array}{l}\text { Infection visits } \\
\text { Per } 1000 \\
\text { inhabitants } \\
\text { per year (\%) }\end{array}$} & \multicolumn{2}{|c|}{ Antibiotic prescriptions } & \multirow{2}{*}{$\begin{array}{l}\text { Infection visits } \\
\text { Per } 1000 \\
\text { inhabitants } \\
\text { per year (\%) }\end{array}$} & \multicolumn{3}{|c|}{ Antibiotic prescriptions } \\
\hline & & $\begin{array}{l}\text { Per } 1000 \\
\text { inhabitants } \\
\text { per year }\end{array}$ & Percent of cases & & $\begin{array}{l}\text { Per } 1000 \\
\text { inhabitants } \\
\text { per year }\end{array}$ & $\begin{array}{l}\text { Percent } \\
\text { of cases }\end{array}$ & $\begin{array}{l}\text { Adjusted relative } \\
\text { risk }^{\mathrm{b}}(95 \% \mathrm{Cl})\end{array}$ \\
\hline Respiratory tract infections & $215(56 \%)$ & 89 & $42 \%$ & $32(62 \%)$ & 17 & $55 \%$ & $1.25(1.24$ to 1.26$)$ \\
\hline Acute bronchitis & $23(6 \%)$ & 11 & $47 \%$ & $2.2(4 \%)$ & 1.0 & $46 \%$ & 0.95 (0.91 to 0.98) \\
\hline Acute otitis media & $23(6 \%)$ & 20 & $85 \%$ & $6.7(13 \%)$ & 6.1 & $91 \%$ & 1.01 (1.00 to 1.02$)$ \\
\hline Chronic Obstructive Pulmonary Disease & $14(4 \%)$ & 2.4 & $18 \%$ & $0.4(1 \%)$ & 0.1 & $34 \%$ & $1.02(0.87$ to 1.19$)$ \\
\hline Influenza & $1.9(0 \%)$ & 0.1 & $6 \%$ & $0.4(1 \%)$ & 0.0 & $4 \%$ & $0.75(0.51$ to 1.11$)$ \\
\hline Pharyngotonsillitis & $28(7 \%)$ & 23 & $80 \%$ & $6.8(13 \%)$ & 5.7 & $84 \%$ & 1.01 (1.00 to 1.02$)$ \\
\hline Pneumonia & $14(4 \%)$ & 9.1 & $67 \%$ & $2.2(4 \%)$ & 1.7 & $76 \%$ & $1.08(1.05$ to 1.10$)$ \\
\hline Sinusitis & $17(5 \%)$ & 14 & $83 \%$ & $1.8(4 \%)$ & 1.6 & $85 \%$ & 1.00 (0.98 to 1.02$)$ \\
\hline Upper respiratory tract infection & $81(21 \%)$ & 8.0 & $10 \%$ & $9.6(19 \%)$ & 0.9 & $9 \%$ & 0.87 (0.83 to 0.92$)$ \\
\hline Other respiratory tract infection & $12(3 \%)$ & 2.2 & $18 \%$ & $1.5(3 \%)$ & 0.4 & $27 \%$ & 1.04 (0.95 to 1.14$)$ \\
\hline Skin and soft tissue infections & $60(16 \%)$ & 26 & $44 \%$ & $6.1(12 \%)$ & 4.1 & $68 \%$ & 1.20 (1.18 to 1.23$)$ \\
\hline Urinary tract infections & $45(12 \%)$ & 36 & $80 \%$ & $7.6(15 \%)$ & 6.4 & $84 \%$ & 1.04 (1.04 to 1.05$)$ \\
\hline Lower urinary tract infections & $34(9 \%)$ & 31 & $90 \%$ & $6.3(12 \%)$ & 5.7 & $89 \%$ & $1.00(1.00$ to 1.01$)$ \\
\hline Other urogenital infections & $10(3 \%)$ & 4.4 & $44 \%$ & $1.3(3 \%)$ & 0.7 & $56 \%$ & 1.07 (1.02 to 1.13$)$ \\
\hline Other infections ${ }^{a}$ & $63(17 \%)$ & 3.8 & $6 \%$ & $6.1(12 \%)$ & 0.4 & $7 \%$ & 0.81 (0.74 to 0.89 ) \\
\hline Total & $382(100 \%)$ & 155 & $41 \%$ & $51(100 \%)$ & 28 & $55 \%$ & \\
\hline
\end{tabular}

${ }^{a}$ Includes eye infections, gastrointestinal infections, and rare infections

${ }^{b}$ Relative risk of antibiotic prescription adjusted for sex and age during out-of-hours compared to in-hours

to the decrease were shorter opening hours at the end of the study, a penalty fee (100 euros) introduced in 2008 for the PHCC for each patient attending the OOHC, and the introduction of a nurse triage system for walk-in patients at $\mathrm{OOHC1.}$

The $\mathrm{OOH}$ antibiotic prescription rate per 1000 inhabitants per year was at the same level in the Netherlands, Sweden, and England (20, 28, and 31 prescriptions, respectively), but higher in Denmark (80 prescriptions) [9, 13, 27]. Two English studies have shown stable or increased $\mathrm{OOH}$ antibiotic prescription rates from 2010 to $2014[8,9]$. In contrast, our study showed a decrease in antibiotic prescription rates.

The main explanation for excess prescribing during $\mathrm{OOH}$ is that infections that are often treated with antibiotics were more common during $\mathrm{OOH}$ visits such as acute media otitis, pharyngotonsillitis, and lower UTIs. The relative risk of antibiotic prescribing was decreased when adjusting for diagnoses. For SSI, the relative risk of receiving antibiotics during $\mathrm{OOH}$ remained elevated 1.20 (95\% CI 1.18-1.23). It was uncommon to prescribe UTI antibiotics without a visit with infection diagnosis during $\mathrm{OOH}$ service (9\% of UTI antibiotic prescriptions were without a visit during $\mathrm{OOH}$ compared to $39 \%$ during $\mathrm{IH}$ ) although it was in line with current guidelines. This fully explained the higher UTI visit rate during $\mathrm{OOH}$.
These results are similar to other European studies when comparing $\mathrm{OOH}$ and $\mathrm{IH}$. A Norwegian comparison of tonsillitis and acute media otitis showed no difference in the prescription rate at OOHCs [33], and a Dutch study showed higher prescription levels during $\mathrm{OOH}$ for common infections and argued that the patients were sicker in the sense that they had more urgent problems that could not wait until the next day based on a revision of the EMR [13].

The remaining excess prescriptions during $\mathrm{OOH}$ after adjusting for diagnosis were estimated, leading to 2.2 more prescriptions per 1000 inhabitants per year compared to $\mathrm{IH}$, which corresponds to $7.9 \%$ of the prescriptions during $\mathrm{OOH}$ and to $1.2 \%$ of all prescriptions during $\mathrm{IH}$ and $\mathrm{OOH}$ together. These prescriptions could partly be explained by sicker patients in need for urgent evaluation and an absence of control visits in the $\mathrm{OOH}$ setting. On the other hand, a reason could be a lower threshold to prescribe during $\mathrm{OOH}$ for example due to high workload or due to limited possibility to arrange for follow-ups.

Apart from the high relative risk of receiving antibiotics for SSI during $\mathrm{OOH}$, there are no apparent areas to intervene. But because the total decrease of antibiotic prescriptions during the study period is $27 \%$ and the excess prescriptions during $\mathrm{OOH}$ are just above $1 \%$ of all antibiotic prescriptions, there 
Table 6 Antibiotic treatment by antibiotic group for the six most common diagnoses between in-hours and out-of-hours

\begin{tabular}{|c|c|c|c|}
\hline \multirow[t]{2}{*}{ Indication } & \multirow[b]{2}{*}{ Choice of antibiotic } & \multicolumn{2}{|c|}{ Prescription ${ }^{a}, \%$} \\
\hline & & In-hours & Out-of-hours \\
\hline Acute bronchitis & Doxycycline & $59 \%$ & $52 \%$ \\
\hline \multirow[t]{4}{*}{$(n=18,970)$} & Phenoxymethylpenicillin & $21 \%$ & $27 \%$ \\
\hline & Amoxicillin & $11 \%$ & $11 \%$ \\
\hline & Macrolides & $5 \%$ & $7 \%$ \\
\hline & Cefadroxil & $2 \%$ & $2 \%$ \\
\hline Acute otitis media & Phenoxymethylpenicillin ${ }^{b}$ & $70 \%$ & $69 \%$ \\
\hline \multirow[t]{4}{*}{$(n=41,419)$} & Amoxicillin & $20 \%$ & $21 \%$ \\
\hline & Macrolides & $4 \%$ & $4 \%$ \\
\hline & Amoxicillin/clavulanate & $2 \%$ & $2 \%$ \\
\hline & Cephalosporins & $2 \%$ & $2 \%$ \\
\hline Lower urinary tract infection & Pivmecillinam ${ }^{\text {b }}$ & $45 \%$ & $46 \%$ \\
\hline \multirow[t]{4}{*}{$(n=59,335)$} & Nitrofurantoin ${ }^{b}$ & $22 \%$ & $20 \%$ \\
\hline & Quinolones & $17 \%$ & $18 \%$ \\
\hline & Trimethoprim & $9 \%$ & $7 \%$ \\
\hline & Cefadroxil & $5 \%$ & $6 \%$ \\
\hline Pharyngotonsillitis & Phenoxymethylpenicillin ${ }^{\mathrm{b}}$ & $78 \%$ & $79 \%$ \\
\hline \multirow[t]{5}{*}{$(n=45,547)$} & Cephalosporins & $9 \%$ & $8 \%$ \\
\hline & Clindamycin & $6 \%$ & $5 \%$ \\
\hline & Macrolides & $3 \%$ & $3 \%$ \\
\hline & Amoxicillin & $2 \%$ & $3 \%$ \\
\hline & Tetracyclines & $2 \%$ & $1 \%$ \\
\hline Pneumonia & Phenoxymethylpenicillin ${ }^{b}$ & $41 \%$ & $45 \%$ \\
\hline \multirow[t]{4}{*}{$(n=17,527)$} & Doxycycline & $38 \%$ & $32 \%$ \\
\hline & Amoxicillin & $9 \%$ & $11 \%$ \\
\hline & Macrolides & $8 \%$ & $7 \%$ \\
\hline & Cefadroxil & $2 \%$ & $2 \%$ \\
\hline Sinusitis & Phenoxymethylpenicillin ${ }^{b}$ & $54 \%$ & $60 \%$ \\
\hline \multirow[t]{4}{*}{$(n=23,070)$} & Tetracyclines & $30 \%$ & $25 \%$ \\
\hline & Amoxicillin & $9 \%$ & $9 \%$ \\
\hline & Macrolides & $2 \%$ & $2 \%$ \\
\hline & Cephalosporins & $3 \%$ & $2 \%$ \\
\hline
\end{tabular}

\footnotetext{
antibiotics with prescribed percentages over $2 \%$ are shown
}

${ }^{\mathrm{b}}$ First-choice antibiotics according to the Swedish prescribing guidelines

would be limited gain from intervening in the $\mathrm{OOH}$ setting.

There were no differences in treatment choice, which corresponds with other quantitative studies from Norway and the Netherlands [13,33] and with a Belgian qualitative study where physicians reported the treatment choice to be the same as during $\mathrm{IH}$, although the threshold to prescribe was lower at OOHCs [11]. In contrast, an English study noted a higher proportion of broad-spectrum antibiotics during $\mathrm{OOH}[8]$.

\section{Strengths}

The data set was complete for infection visits and antibiotic prescriptions in primary care in a region in Sweden. Because the whole region was included, the data were real-life data without any selection due to study participation. Also, the same EMR system was used during the study period thus decreasing the risk for information errors. Because writing a diagnosis was compulsory for all visit records, very few diagnoses were missing. All $\mathrm{OOH}$ infection visits and prescriptions were included, which enabled comparisons between IH and 
$\mathrm{OOH}$, adjusting for sex, age groups, and diagnoses. The comparison between $\mathrm{IH}$ and $\mathrm{OOH}$ is relevant for Sweden as a whole and for other countries with similar $\mathrm{OOH}$ settings.

\section{Limitations}

Limitations of the study include that no validation of diagnoses by examining the EMR was done. Also, the reason why some antibiotics are prescribed without a coded infection diagnosis has not been explored. A lower threshold to diagnose infections and to prescribe antibiotics in the $\mathrm{OOH}$ setting cannot be ruled out but would also be hard to verify in the EMR. Other antibiotics than oral and parenteral antibiotics (ATC code J01) are missing in the dataset, such as antibiotics in topical skin and eye preparations. The antibiotic rate for the elderly ( $>80$ years) might be underestimated due to partly missing data for patients with medication administered through a dispensing system. Furthermore, we could not measure the rate of delayed prescribing because we did not have access to pharmacy dispensing data. The common way of delayed prescribing in Sweden is that the patient receives an electronic prescription but is recommended to wait a few days before collecting the prescription [34].

\section{Conclusions}

Although the infection visit rate was unchanged, there was a significant reduction in antibiotic prescribing, especially to children and for RTIs. The increased antibiotic prescribing rate during $\mathrm{OOH}$ was small when adjusted for age, sex, and diagnosis, and no excess prescribing of broad-spectrum antibiotics was seen. Therefore, interventions selectively aiming at $\mathrm{OOHCs}$ seem to be unmotivated in a low-prescribing context.

\section{Supplementary information}

Supplementary information accompanies this paper at https://doi.org/10. 1186/s12879-020-05334-7.

Additional file 1. Infection diagnoses selected to be included in the Kronoberg Infection Database in Primary care 2006-2014. Description: The total number of patients and visits are shown for all providers (physicians, nurses) and for physicians only.

\section{Abbreviations}

ATC: Anatomical therapeutic chemical classification; EMR: Electronic medical records; IH: In-hours; KIDPC: Kronoberg Infection database in primary care; OOH: Out-of-hours; OOHC: Out-of-hours centre; PHCC: Primary healthcare centre; PRIS: Primary care record of infections in Sweden database; RTI: Respiratory tract infection; SSI: Skin and soft tissue infection; UTI: Urinary tract infection

\section{Acknowledgements}

We thank Anna Lindgren for assistance with the statistical analysis.

\section{Authors' contributions}

$\mathrm{OC}$ and $\mathrm{KH}$ initiated the study. OC managed and validated the KIDPC dataset. OC carried out the analysis of the data and drafted the manuscript, which was evaluated by $\mathrm{KH}, \mathrm{MT}$, and $\mathrm{KE}$. All authors critically revised and approved the final manuscript.

\section{Funding}

This project was funded by a research grant from R\&D Kronoberg, Region Kronoberg, the Medical Research Council of Southeast Sweden (FORSS) and Southern Regional Health Care Committee, Sweden. The funders had no role in the design of the study and collection, analysis, and interpretation of data and in writing the manuscript. Open access funding provided by Lund University.

\section{Availability of data and materials}

The datasets used and/or analysed during the current study are available from the corresponding author on reasonable request.

\section{Ethics approval and consent to participate}

Ethical approval was obtained from the Regional Ethical Review Board in Linköping, Sweden to create the KIDPC database for research purposes (Dnr 2014/121-31). Permissions to extract data were obtained from all the managers of the PHCC and were included in the application of ethical approval. Confidentiality of the patients was ensured by one-way encrypted identification numbers. As this retrospective study contains only anonymous patient data, the Regional Ethical Review Board did not require informed consent from the patients.

\section{Consent for publication}

Not applicable.

\section{Competing interests}

The authors declare that they have no competing interests.

\section{Author details}

${ }^{1}$ Växjöhälsan Primary Healthcare Center, VC Växjöhälsan, Hjortvägen 1, 35245 Växjö, Sweden. ${ }^{2}$ Department of Research and Development, Region Kronoberg, Växjö, Sweden. ${ }^{3}$ Department of Clinical Sciences in Malmö, Family Medicine, Lund University, Malmö, Sweden. ${ }^{4}$ Lundbergsgatan Primary Health Care Centre, Malmö, Sweden. ${ }^{5}$ Department of Medical Biosciences, Clinical Chemistry, Umeå University, Umeå, Sweden. ${ }^{6}$ Futurum, Region Jönköping County and Department of Health, Medicine and Caring Sciences, Linköping University, Linköping, Sweden.

Received: 22 April 2020 Accepted: 10 August 2020

Published online: 20 August 2020

\section{References}

1. WHO. Global Action Plan on Antimicrobial Resistance. Geneva: WHO; 2015.

2. Costelloe C, Metcalfe C, Lovering A, Mant D, Hay AD. Effect of antibiotic prescribing in primary care on antimicrobial resistance in individual patients: systematic review and meta-analysis. BMJ. 2010;340:c2096.

3. Cars O, Molstad S, Melander A. Variation in antibiotic use in the European Union. Lancet. 2001;357(9271):1851-3.

4. Bjerrum L, Boada A, Cots JM, Llor C, Fores Garcia D, Gahrn-Hansen B, et al. Respiratory tract infections in general practice: considerable differences in prescribing habits between general practitioners in Denmark and Spain. Eur J Clin Pharmacol. 2004;60(1):23-8.

5. Tyrstrup M, van der Velden A, Engstrom S, Goderis G, Molstad S, Verheij T, et al. Antibiotic prescribing in relation to diagnoses and consultation rates in Belgium, the Netherlands and Sweden: use of European quality indicators. Scand J Prim Health Care. 2017:35(1):10-8.

6. Willekens M, Giesen P, Plat E, Mokkink H, Burgers J, Grol R. Quality of afterhours primary care in the Netherlands: adherence to national guidelines. BMJ Qual Saf. 2011;20(3):223-7.

7. Adriaenssens N, Bartholomeeusen S, Ryckebosch P, Coenen S. Quality of antibiotic prescription during office hours and out-of-hours in Flemish primary care, using European quality indicators. Eur J Gen Pract. 2014;20(2): 114-20.

8. Edelstein M, Agbebiyi A, Ashiru-Oredope D, Hopkins S. Trends and patterns in antibiotic prescribing among out-of-hours primary care providers in England, 2010-14. J Antimicrob Chemother. 2017;72(12):3490-5.

9. Hayward GN, Fisher RF, Spence GT, Lasserson DS. Increase in antibiotic prescriptions in out-of-hours primary care in contrast to in-hours primary 
care prescriptions: service evaluation in a population of 600000 patients. Antimicrob Chemother. 2016;71(9):2612-9.

10. Huibers L, Moth G, Christensen MB, Vedsted P. Antibiotic prescribing patterns in out-of-hours primary care: a population-based descriptive study. Scand J Prim Health Care. 2014;32(4):200-7.

11. Colliers A, Coenen S, Remmen R, Philips H, Anthierens S. How do general practitioners and pharmacists experience antibiotic use in out-of-hours primary care? An exploratory qualitative interview study to inform a participatory action research project. BMJ Open. 2018;8(9):e023154

12. Colliers A, Adriaenssens N, Anthierens S, Bartholomeeusen S, Philips H, Remmen R, et al. Antibiotic Prescribing Quality in Out-of-Hours Primary Care and Critical Appraisal of Disease-Specific Quality Indicators. Antibiotics (Basel). 2019;8(2):1-10.

13. Debets VE, Verheij TJ, van der Velden AW. Antibiotic prescribing during office hours and out-of-hours: a comparison of quality and quantity in primary care in the Netherlands. Br J Gen Pract. 2017;67(656):e178-e86. https://doi.org/10.3399/bjgp17X689641.

14. Molstad S, Lundborg CS, Karlsson AK, Cars O. Antibiotic prescription rates vary markedly between 13 European countries. Scand J Infect Dis. 2002; 34(5):366-71.

15. Tyrstrup M, Beckman A, Molstad S, Engstrom S, Lannering C, Melander E, et al. Reduction in antibiotic prescribing for respiratory tract infections in Swedish primary care- a retrospective study of electronic patient records. BMC Infect Dis. 2016;16(1):709.

16. Nord M, Engström S, Mölstad S. Mycket varierande förskrivning av antibiotika i primärvården [very varied prescription of antibiotics in primary care. Low adherence to guidelines in throat infections, as shown by diagnosis-based data]. Läkartidningen. 2013;110(27-28):1282-4.

17. Molstad S, Lofmark S, Carlin K, Erntell M, Aspevall O, Blad L, et al. Lessons learnt during 20 years of the Swedish strategic programme against antibiotic resistance. Bull World Health Organ. 2017;95(11):764-73.

18. Läkemedelsverket. Läkemedelsbehandling vid rinosinuit Behandlingsrekommendation [pharmacological treatment of rhinosinusitis recommended treatment]. Information från läkemedelsverket. 2005;2005(3):7-13.

19. Läkemedelsverket. Nedre urinvägsinfektion (UVI) hos kvinnor [lower urinary tract infections in women]. Information från läkemedelsverket. 2007;2007(2):8-45.

20. Läkemedelsverket. Farmakologisk behandling av bakteriella hud- och mjukdelsinfektioner - ny rekommendation [pharmacological treatment of bacterial skin- och soft tissue infections - new recommendation] Information från läkemedelsverket. 2009;2009(5):16-58.

21. Läkemedelsverket. Diagnostik, behandling och uppföljning av akut mediaotit [Diagnosis, treatment and follow-up of acute otitis media]. Information från läkemedelsverket. 2010;2010(5):13-24.

22. Läkemedelsverket. Handläggning av faryngotonsilliter i öppenvård - ny rekommendation [treatment of pharyngotonisillitis in outpatient care - new recommendation]. Information från läkemedelsverket. 2012;2012(6):18-66.

23. Statistics Sweden. Population by region, marital status, age and sex. Year 1968-2018. https://www.scb.se/en/finding-statistics/statistics-bysubject-area/population/population-composition/population-statistics/ . Accessed 11 Aug 2019

24. Socialstyrelsen. Klassifikation av sjukdomar och hälsoproblem 1997 Primärvård (KSH97-P) [Classification of diseases and health problems 1997 Primary Care]. Socialstyrelsen; 1997.

25. Folkhälsomyndigheten. Att följa upp förskrivning av antibiotika i primärvård - en vägledning [To follow antibiotic prescription in primary health care - a guide]. Solna: Folkhälsomyndigheten; 2016. https://www. folkhalsomyndigheten.se/publicerat-material/publikationsarkiv/a/vagledningfolja-upp-forskrivning-antibiotika-primarvard/. Accessed 14 Apr 2020.

26. Swedres-Svarm 2014. Consumption of antibiotics and occurrence of antibiotic resistance in Sweden. Solna/Uppsala, Sweden: Public Health Agency of Sweden and National Veterinary Institute; 2015. https://www. folkhalsomyndigheten.se/publicerat-material/publikationsarkiv/s/swedressvarm-2014/. Accessed 14 Apr 2020.

27. Huibers L, Moth $G$, Andersen M, van Grunsven P, Giesen P, Christensen MB, et al. Consumption in out-of-hours health care: Danes double Dutch? Scand J Prim Health Care. 2014;32(1):44-50.

28. Majeed A, Moser K. Age- and sex-specific antibiotic prescribing patterns in general practice in England and Wales in 1996. Br J Gen Pract. 1999; 49(446):735-6.

29. Parviainen S, Saastamoinen L, Lauhio A, Sepponen K. Outpatient antibacterial use and costs in children and adolescents: a nationwide register-based study in Finland, 2008-16. J Antimicrob Chemother. 2019; 74(8):2426-33.

30. Strama. The Swedish strategic programme against antibiotic resistance. https://strama.se/. Accessed 23 Jun 2020.

31. Socialdepartementet Regeringskansliet. Strategi för ett samordnat arbete mot antibiotikaresistens och vårdrelaterade sjukdomar - Prop. 2005/06:50 [Strategy to prevent antibiotic resistance and healthcare-associated infections]. Stockholm 2005. https://www.regeringen.se/rattsliga-dokument/ proposition/2005/12/prop.-20050650/. Accessed 20 Jan 2020.

32. Tegmark-Wisell $K$, Cars O. Förbättrad antibiotikaanvändning i fokus $i$ regeringens patientsäkerhetssatsning [Focus on improved antibiotics use in the government's patient safety initiative]. Läkartidningen. 2011;108(3):96-7.

33. Fagan M. Is otitis and tonsillitis handled in the same way within normal working hours and out-of-hours? Tidsskrift for den Norske laegeforening. 2008:128(20):2340-2.

34. Little P, Moore M, Kelly J, Williamson I, Leydon G, McDermott L, et al. Delayed antibiotic prescribing strategies for respiratory tract infections in primary care: pragmatic, factorial, randomised controlled trial. BMJ. 2014;348:g1606

\section{Publisher's Note}

Springer Nature remains neutral with regard to jurisdictional claims in published maps and institutional affiliations.

\section{Ready to submit your research? Choose BMC and benefit from:}

- fast, convenient online submission

- thorough peer review by experienced researchers in your field

- rapid publication on acceptance

- support for research data, including large and complex data types

- gold Open Access which fosters wider collaboration and increased citations

- maximum visibility for your research: over $100 \mathrm{M}$ website views per year

At BMC, research is always in progress.

Learn more biomedcentral.com/submissions 